\title{
THE IMPORTANCE OF OTOMICROSCOPY IN THE DIAGNOSIS AND TREATMENT OF THE SO-CALLED SECRETORY MIDDLE-EAR CATARRH
}

\author{
By E. LUSCHER (Bern)
}

By secretory or exudative catarrh of the middle ear, the Viennese school under H. Neumann mean the special form of middle-ear catarrh which is accompanied by a serous or mucous discharge in the tympanum, and is thereby to be distinguished from the ordinary dry middle-ear catarrh, or dry Eustachian obstruction. Unlike acute inflammation proper of the middle ear, all symptoms of inflammation are lacking. The tympanic membrane is pale, or at the most has only a slight injection of the blood-vessels. The patient has no pain, but complains of considerable difficulty in hearing, as in the case of obstructed tubes, combined mostly with an oppressive and "stuffed-up " feeling in the ear in question.

Secretory catarrh occurs in acute or chronic forms, and is frequently to be met with as the result of acute and chronic rhino-pharyngitis, in all forms of obstruction of the Eustachian tubes, also with tumours of the pharynx and, finally, without any disease as a visible cause. Cases occur frequently in practice, as particularly noted by the Viennese school, but in the chronic form are often confused with dry middle-ear catarrh, on debatable grounds, and are hence often wrongly and unsuccessfully treated for weeks.

Secretory catarrh is indeed a well-defined affection as far as symptoms and clinical treatment are concerned but, however, the atiology and pathogenesis are not clear, and many points remain to be discussed. As in the case of dry catarrh of the middle ear, it shows on the one hand all stages of development, to acute inflammation proper of the middle ear and, on the other, a pure occlusion of the Eustachian tubes, without affection of the middle ear. While Bezold, ${ }^{3}$ Scheibe, ${ }^{12}$ Brock $^{5}$ and others are of opinion, on the basis of bacteriological and 


\section{So-called Secretory Middle-Ear Catarrh}

histological investigations, that the serous discharge is sterile and a pure hydrops ex vacuo as the result of the closing of the tubes, Brieger, ${ }^{4}$ Manasse, ${ }^{4}$ Wagener, ${ }^{4} \mathrm{Kümmel}^{4}$ and others emphasize an inflammatory cause, and consider the discharge as an exudation. Forschner ${ }^{6}$ has lately come to the opinion, by reason of his own investigations, that the bacteriology is not quite clear. The chemical analyses of the serous discharge made by Schlander, ${ }^{13}$ and also by Goedel and Kutscher ${ }^{7}$ have demonstrated that the albuminous content of the fluid corresponds partly to an exudation and partly to a transudation, so that in any case inflammatory and non-inflammatory factors play their part as the cause of the discharge into the tympanum. The discharge has an exudatory character in the case of secretory catarrh together with acute rhinitis and rhino-pharyngitis which, according to Forschner, ${ }^{6}$ is the most frequent. But if an acute inflammation is lacking as a cause, the discharge can correspond to either a transudation or to an exudation. This is so in the case of Eustachian occlusion through tumours in the neighbourhood of the pharyngeal orifice. Ruttin ${ }^{\text {Io, } x}$ is here of the opinion that it is a question of a congestion transudate, while in other cases of sanguineous exudation he assumes a fluid secretion of the degenerated mucous membrane of the middle ear. Finally, the mucous content of the fluid which is sometimes considerable, indicates the participation of the gland cells of the tubes, whereby the mucus is forced into the tympanum by suction (passive exudation according to Alexander ${ }^{\mathrm{T}}$ ). It would lead too far to enter here into these debatable questions, an exhaustive literature of which has been drawn up by Blegvad. ${ }^{2}$

Secretory catarrh must be distinguished on the one hand from a mild acute inflammation of the middle ear, and on the other from dry catarrh of the middle ear or the Eustachian tubes. The lack of acute subjective and objective signs of irritation, i.e. lack of myringitis, excludes acute inflammation of the middle ear. As I have already remarked, the border lines are indefinite. Much more difficult is the differential diagnosis from dry middle-ear catarrh or from Eustachian obstruction, with which it agrees in all its symptoms. Here the diagnosis of secretory catarrh is based on the evidence of fluid discharge in the tympanum. In the case of an intact tympanic membrane there exists only one sure sign, i.e. the level-line caused by the upper limit of the fluid. The classic description of transudation 


\section{E. Lüscher}

and exudation lines in the middle ear by Politzer ${ }^{9}$ in 1869 is still valid for ordinary otoscopy and is repeated in the same terms in all handbooks. The fluid in the tympanum forms either the well-known line, slightly concave above or conical, or formed into bubbles through air mixture. In both cases the quantity of fluid must be fairly great, so that the cavum tympani is filled from the base up to a certain height. Hence small quantities of secretion escape attention, and thus is explained the fact that, in spite of the relatively frequent occurrence of such discharges, the so-called level-lines are seldom to be seen. Cases without level-lines are diagnosed by the Viennese school through a number of indirect symptoms. According to Alexander, ${ }^{x}$ one indication of the fluid in the middle ear is a pronounced yellow discolouration of the tympanic membrane, also an increased watery shininess in cases of a certain convexity and, furthermore, a narrowing of the handle of the malleus. Sometimes the patient perceives a feeling of a falling drop-or moist râles in catheterization suggest a discharge in the tympanum. But these signs of secretory catarrh are quite uncertain, and do not go beyond a suppositional diagnosis, which considerably complicates the decision to effect a sometimes necessary paracentesis. For this reason, secretory catarrh is frequently confused in practice with simple Eustachian obstruction or dry catarrh of the middle ear.

This difficulty in differential diagnosis is considerably mitigated through the otomicroscope (Lüscher ${ }^{8}$ ), as in investigations with the ear microscope giving ten or more magnifications, the limits of the fluid in the middle ear reveal themselves especially clearly. According to the incidence of the light, they appear as white, golden-yellow or as dark grey or blue-black lines. They generally form sharply defined, partly doubleedged bands, with a breadth up to $0 \cdot I \mathrm{~mm}$. But such lines are not always, however, fluid limits. The fact that freely displaceable discharges exist in certain cases in the tympanum is easily verified by the Siegle pneumatic speculum. Under pressure and suction in the tympanum, and the volume changes of the tympanum caused thereby, the fluid edges change their shape and position, as I shall describe in more detail later.

The colour of the stripes and lines is conditioned by the breaking of the light on the curved surface of the fluid. In the case of total deflection, the line appears black, in the case of total reflection, white, while the golden-yellow shimmer is to be 


\section{So-called Secretory Middle-Ear Catarrh}

attributed partly to the yellow colour of the serous exudation, and partly to the light reflection on the yellow mucosa over the promontory. This last opinion is further strengthened by the fact that greater atrophies of the pars tensa show a conspicuous yellow tone under greater magnification.

The shape and position of the fluid levels thus rendered visible are far more numerous than those that have been described hitherto for large quantities of exudation with a simple level-line. For it is often a question of observing small quantities which are held by capillarity in the narrow tympanum in the neighbourhood of the umbo in different forms. Only when the effect of capillary force has been annulled, or at least strongly reduced, through the convexity of the tympanic membrane as the result of much fluid, can the simple level-lines be formed, in which capillarity is only occasionally evident in the drawn-up form, in the region of the umbo.

A particularly striking and easily understandable example of capillary effect is the " hanging drop " behind the umbo, as is demonstrated in the following case.

CASE I.-P.M., 25-year-old man. Taken into hospital on 27.6.30. No previous trouble with ears. Discovery of slight deafness when recruiting five years ago. Slow increase without discomfort, for the last month some deafness also on the left side. Condition on 27.6.30. Tympanum on both sides strongly retracted and dull, pale and intact. Hearing test : Whispered numbers, left: against the pinna, right, $o$. Conversation, left : $20-30 \mathrm{~cm}$., right : against the pinna. Rinne strongly negative. Schwabach slightly shortened. Lower tone limits on both sides strongly raised, upper tone limits normal.

Diagnosis: Adhesive changes in both middle ears with a high degree of deafness of mixed type.

Otomicroscopical inspection of the left ear (28.7.30).

FIG. I. Behind the umbo hangs an oval fluid drop of about I. $5 \mathrm{~mm}$. in diameter, edged on one side by a sharp goldenyellow and on the other partly blackish, line.

FIG. 2. The same drop a few days later (2.8.30) drawn out to a pointed pear shape.

FIG. 3. Blown-out drop of mucous-serous exudation after paracentesis and inflation.

Such forms arise because a fluid drop is held in the narrowest part of the tympanum between the umbo and the promontory. 


\section{E. Lüscher}

If the quantity of secretion is slight, the drop surrounds the umbo in an oval shape but, as it increases, it is drawn out to a point through its own weight. Under pressure of the Siegle pneumatic speculum the drop spreads itself out on the surface as a result of the umbo approaching the promontory ; if drawn, it contracts together to fill up the greater space between the two surfaces. The quantity of fluid contained in such drops is naturally very small, so that in this way already a very slight discharge in the tympanum can be shown.

The following case shows an irregular light yellow fluid line :

CASE II.-A man, aged 58 years, taken into hospital on 29.7.33.

Complete Eustachian occlusion on the right side caused by lymphosarcoma of the epipharynx.

Otomicroscopic inspection on II.I0.33 (Fig. 4).

The fluid limit appears as a ca. $0 \cdot 1 \mathrm{~mm}$. wide light yellow stripe moving irregularly about the umbo. The exudation causes the tympanic membrane to appear somewhat darker than the air-filled part, obviously as a result of the lack of light-reflection on the inner surface of the tympanic membrane. In shade the two parts are, however, alike.

Similarly several exudation lines are often to be seen. In these cases also the form of the lines is determined by capillary force.

It is superfluous to go into the well-known forms of the classical level-lines, as in this connection Otomicroscopy has yielded no further details. Also the findings under air-mixture have already been described. Otomicroscopy allows us, however, to distinguish two forms which have hitherto not been held apart. If but little fluid is present, the air blown in leads to foaming, i.e. air bubbles are formed. The following Fig. 5 is an example of this.

CASE III.-A man, aged $5^{8}$ years.

Fig. 5 shows the finding of Fig. 4 after inflation. The transudation lies dispersed as froth on the edges of the tympanum, especially in the hypotympanum.

If considerable fluid and but little air be present, flattened fluid drops arise, separated from one another by dark air fissures. (See Fig. 6.) 
The IMportaxce of Otonicroscopy in the DLagxosis and Treatuext of the so-called Sicretory Mindle-Ear Catarrh.-F. Lёscher

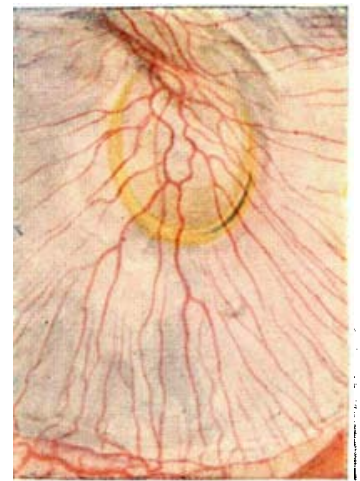

FIG. I.

Male, 25 years: Hanging secretion-drop between umbo and promontory.

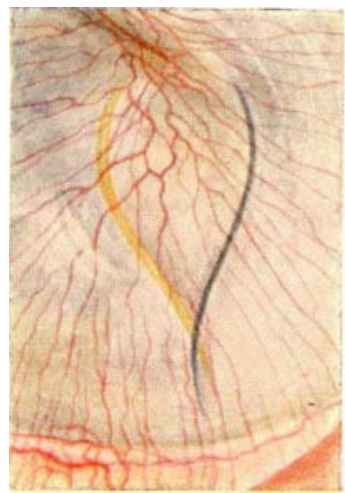

I'IG. 2.

Male, 25 years: The same drop a few days later.

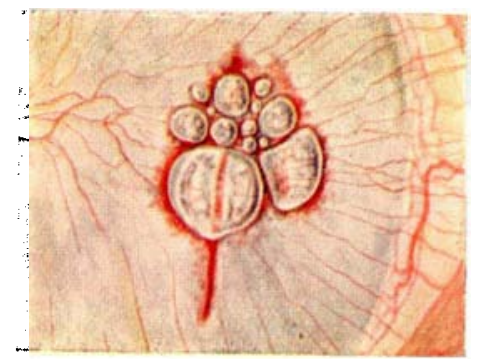

FIG. 3 .

Male, 25 years: Paracentesis with blown out drop. 
Downloaded from https:/www.cambridge.org/core. University of Basel Library, on 11 Jul 2017 at 08:19:53, subject to the Cambridge Core terms of use, available at https:/www.cambridge.org/core/terms. https://doi.org/10.1017/S0022215100042778 


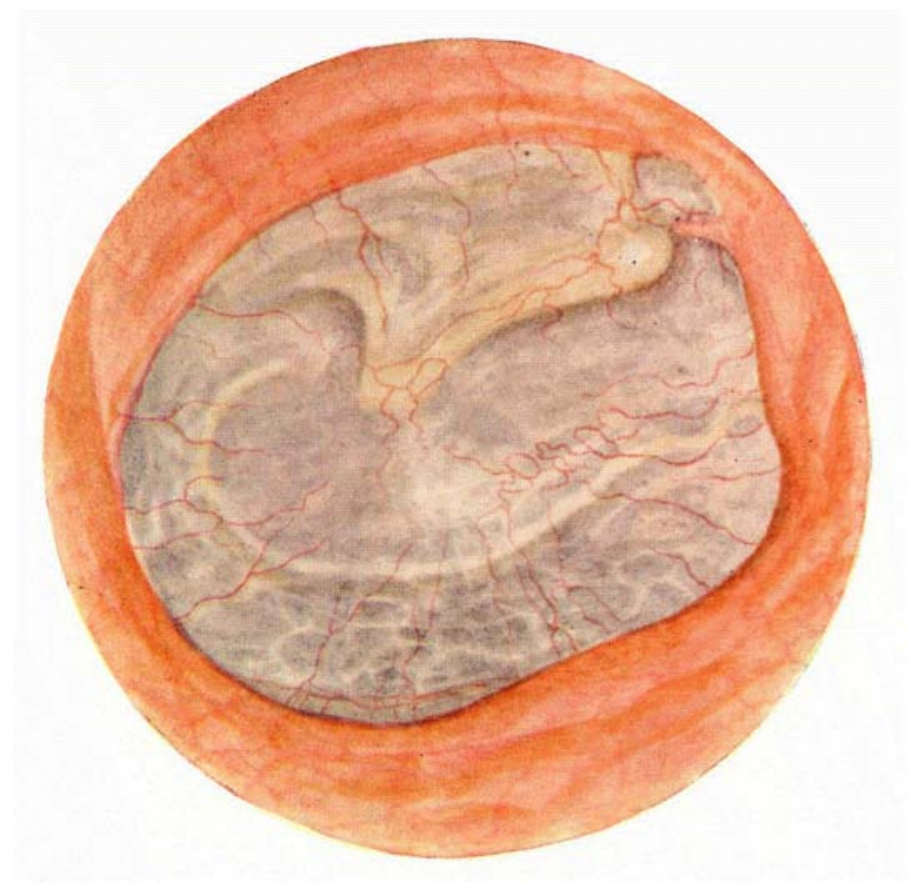

FIG. 4 .

Hale, 58 years: Irregular fluid line. Eustachian obstruction caused by lymphosarcoma. 
Downloaded from https:/www.cambridge.org/core. University of Basel Library, on 11 Jul 2017 at 08:19:53, subject to the Cambridge Core terms of use, available at https:/www.cambridge.org/core/terms. https://doi.org/10.1017/S0022215100042778 


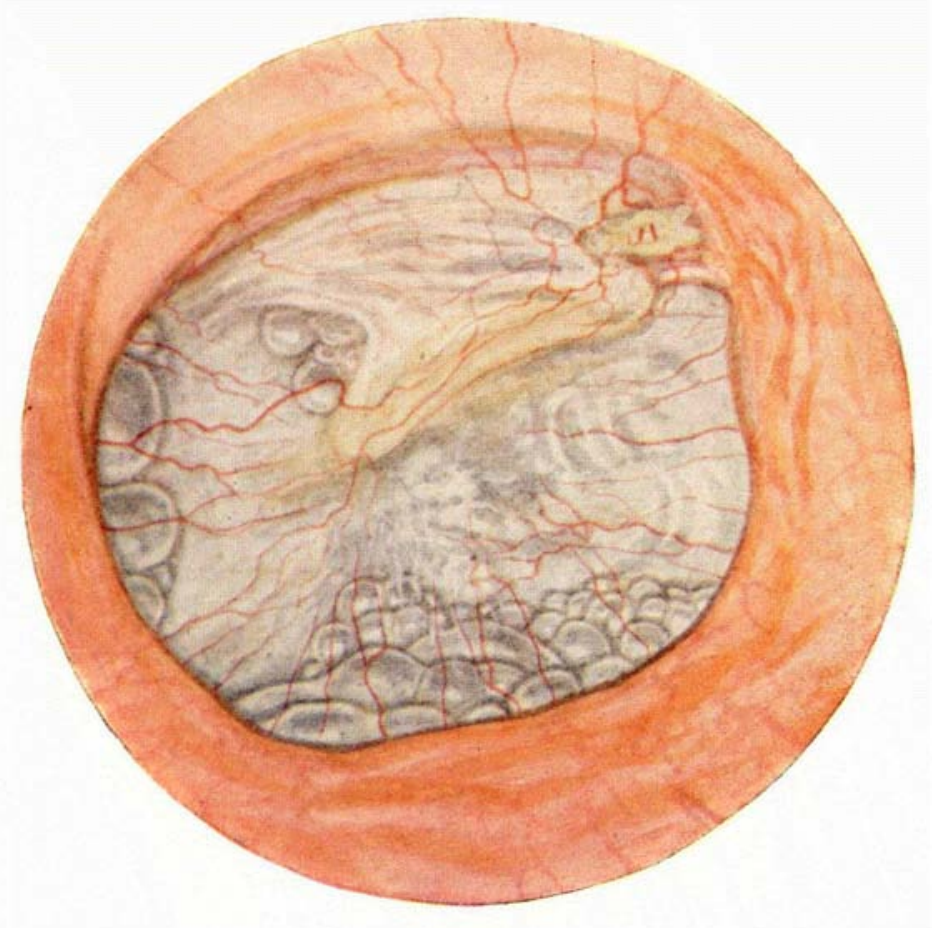

FIG. 5 .

Male, $5^{8}$ years: Transudation foam. Eustachian obstruction caused by lymphosarcoma. 
Downloaded from https:/www.cambridge.org/core. University of Basel Library, on 11 Jul 2017 at 08:19:53, subject to the Cambridge Core terms of use, available at https:/www.cambridge.org/core/terms. https://doi.org/10.1017/S0022215100042778 


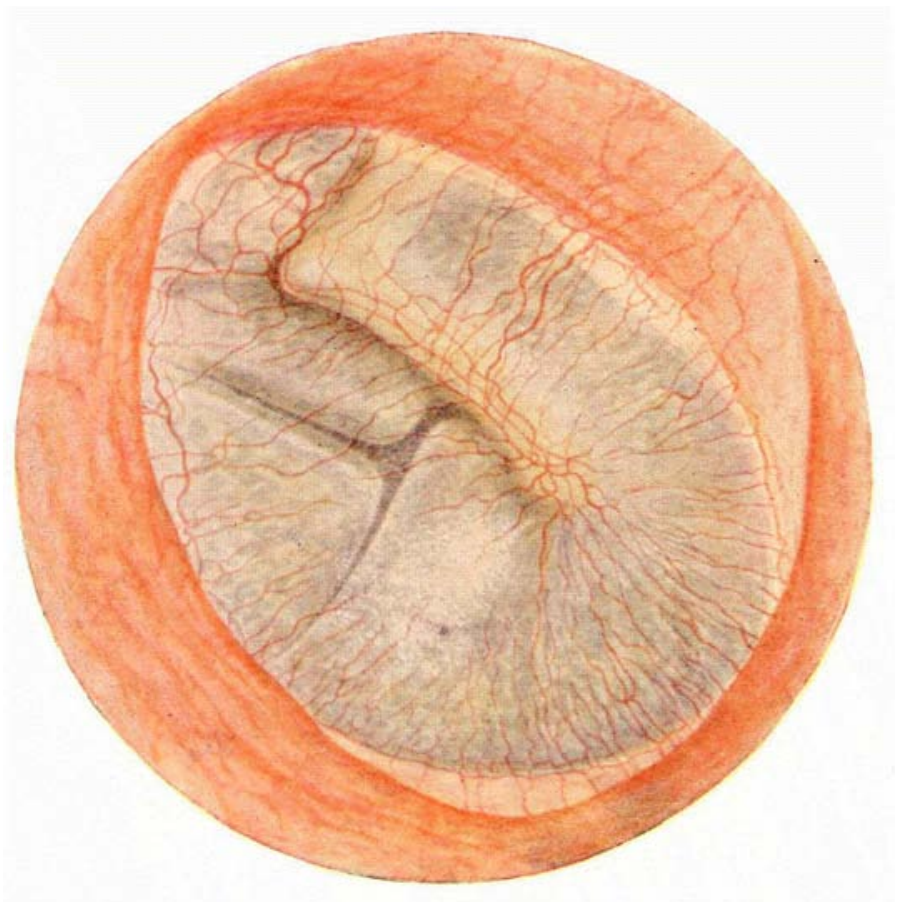

FIG. 6.

Female, 62 years: Transudation drops with air-fissure. Eustachian obstruction caused by lymphosarcoma. 
Downloaded from https:/www.cambridge.org/core. University of Basel Library, on 11 Jul 2017 at 08:19:53, subject to the Cambridge Core terms of use, available at https:/www.cambridge.org/core/terms. https://doi.org/10.1017/S0022215100042778 


\title{
So-called Secretory Middle-Ear Catarrh
}

\author{
CASE IV. A woman, aged 62 years. Taken into hospital \\ on $\mathrm{I} I .5 \cdot 34$. \\ Fig. 6. Transudation with air fissures in the middle ear \\ (lymphosarcoma of the pharynx). \\ The rounded edges of the exudation are clearly distinguished, \\ partly divided by a branching air fissure. \\ Except for its outer edges, the discharge of the tympanum \\ per se is mostly not recognizable with certainty. Only in few \\ cases have I been able to verify the alleged conspicuous yellow \\ colouring of the tympanic membrane, as emphasized by \\ Politzer, ${ }^{9}$ Alexander ${ }^{\mathbf{r}}$ and others (Fig. I). As a rule, the \\ appearance of the tympanic membrane is not specially altered \\ by the presence of a serous discharge, so that only the described \\ fluid lines can be taken as a sure sign of a discharge in the \\ tympanum.
}

While ordinary Otoscopy knows only the classical levellines and possible bubble-formation, under investigation with the ear microscope, and according to the quantity of fluid and its air content, the following five different forms of discharge in the tympanum can be recognized :

I. Hanging drop behind the umbo.

2. Irregular fluid lines resulting from capillary forces.

3. Classical level-lines.

4. Liquid froth composed of air bubbles.

5. Fluid drops with air fissures.

By means of these otomicroscopic findings the diagnosis of secretory catarrh or discharge in the tympanum is rendered certain in many cases, where it was formerly based on uncertain and indirect evidence. Even during treatment, control with the ear microscope is important as with its aid the success of the treatment as regards the elimination of the discharge can be ascertained objectively. If the discharge does not disappear after a few inflations, paracentesis is necessary. This decision is not difficult when the discharge can be directly seen, and in addition the paracentesis of the non-inflamed tympanic membrane is painless, and can be carried out without the use of anæsthesia. Case I demonstrates how even small quantities of secretion in the hanging drop can be blown out from the middle ear through a paracentesis followed by inflation.

Here, as in other spheres, otomicroscopy is an important step forward in practice and represents an important aid for diagnosis and treatment. 


\section{E. Lüscher}

\section{Summary}

I. The diagnosis of secretory middle-ear catarrh is based on the demonstration of a fluid discharge in the tympanum.

2. This demonstration is considerably simplified by investigation with the ear microscope of ten or more magnifications, because the limits of the discharge in the tympanum appear unmistakably and with great clarity, even the smallest quantities of fluid being visible.

3. Otomicroscopy permits the recognition of the following five forms of discharge in the tympanum, according to the amount of the fluid and the air mixture :

I. Hanging drop behind the umbo.

2. Irregular fluid lines resulting from capillary forces.

3. Classical surface lines.

4. Liquid froth composed of air bubbles.

5. Liquid drops with air fissures.

4. Otomicroscopy, therefore, offers an important practical aid for the diagnosis and treatment of secretory middle-ear catarrh.

\section{REFERENCES}

I Alexander : Ohrenkrankheiten im Kindesalter, Leipzig, 1927.

2 Blegvad: Monatsschr. Ohrenheilk., lxvi., 32, 1932.

3 BEZOLD : Berlin. klin. Wschr., I883.

4 Brieger, Manasse, Kümmel: Deutsch. otol. Ges. Kiel, igi4, S.7Iff.

5 Brock : Verh. deutsch. otol. Ges. Kiel, I914, S.59.

6 Forschner: Verh. Ges. deutsch. Hals-, Nasen- und Ohrenärzte, 1925, 477 .

7 Goedel and Kutscher: Verh. Ges. deutsch. Hals-, Nasen- und Ohrenärzte, I933, S.265.

8 LÜSCHER: Zeitschr. Hals- u.s.w. Heilk., xvii., 403, 1927.

9 Politzer: Wien. medizin. Presse, i 869.

ro Rutrin: Mschr. Ohvenheilk., lxiii., 986, I929.

I Derselbe: Verh. Ges. deutsch. Hals-, Nasen- und Ohrenärzte, 1925, $4^{8} \mathrm{I}$.

I2 SCHEIBE: Zeitsch. Ohrenheilk., xxiii.

13 Schlander: Monatschr. Ohrenheilk., lxvi., 278, I932.

Die Diagnose des sekretorischen Mittelohrkatarrhs stützt sich auf den Nachweis einer flüssigen Absonderung in der Paukenhöhle. Durch die Verwendung eines Ohrmikroskops mit zehn- oder mehrfacher Vergrösserung ist diese Flüssigkeitsansammlung leicht nachweisbar, da der Flüssigkeitsspiegel in der Paukenhöhle deutlich

$$
460
$$




\section{So-Called Secretory Middle-Ear Catarrh}

sichtbar ist, sogar bis zur kleinsten Sekretmenge. Mit dem Ohrmikroskop können folgende 5 Arten der Absonderung unterschieden werden :

(I) ein hängender Tropfen hinter dem Umbo.

(2) unregelmässige Flüssigkeitslinien von der Kapillaranziehung herrührend.

(3) typische horizontale Linien.

(4) flüssiger Schaum, hauptsächlich aus Luftbläschen bestehend.

(5) Flüssigkeitstropfen mit dazwischen liegendem Luftraum.

Die Ohrmikroskopie bildet eine wertvolle Hülfe in der Diagnose und Behandlung des Mittelohrkatarrhs.

Le diagnostic de l'otite moyenne exsudative est basé sur la constatation d'un exsudat séreux provenant de la caisse. Cette constatation est considérablement simplifiée par l'oto-microscope qui peut grossir dix fois et même plus parceque le niveau de la sécrétion dans la caisse est clairement visible ainsi que les plus plus petits épanchements. Grâce à l'oto-microscopie, on peut reconnaître les cinq formes d'écoulement suivantes : (I) Goutte pendante derrière l'ombilic. (2) Lignes fluides irrégulières résultant de l'attraction capillaire. (3) Lignes horizontales classiques. (4) Mousse liquide composée principalement de bulles d'air. (5) Gouttes de liquide séparées par de l'air. L'oto-microscopie fournit une aide précieuse pour le diagnostic et le traitement de l'otite moyenne exsudative. 